\title{
APRESENTAÇÃO: DOSSIÊ QUEŞTÕES SOCIOAMBIENTAIS E ETNOBIODIVERSIDADE
}

Flávio Bezerra Barros (Universidade Federal do Pará - Campus de Belém) flaviobb@ufpa.br

Roberta Sá Leitão Barboza (Universidade Federal do Pará - Campus de Bragança) betabarboza@gmail.com Luis Júnior Costa Saraiva (Universidade Federal do Pará - Campus de Bragança) luisjsaraiva@yahoo.com.br

Com imenso regozijo apresentamos o dossiê Questões Socioambientais e Etnobiodiversidade, que reúne aqui 19 artigos e 5 ensaios fotográficos inéditos. Este número da Amazônica: Revista de Antropologia abriga parte dos trabalhos apresentados durante o II Seminário de mesmo nome, ocorrido entre 25 e 27 de outubro de 2016, em Bragança/PA. O dossiê guarda consigo uma história de diálogos, de travessias e experimentações de incertezas. 
O termo diálogo se justifica por causa dos encontros entre pesquisadores acadêmicos e pesquisadoras acadêmicas com pesquisadores e pesquisadoras tradicionais (povos e comunidades tradicionais) com os quais interagimos e construímos em parceria epistemologias, que alguns têm chamado de epistemologias do sul, como Boaventura de Sousa Santos aclama. Invertendo a ordem, a palavra incerteza abriga em si a inquietação que nos penetra profundamente sobre o quanto é difícil levar a cabo o exercício da trans e da interdisciplinaridade. Abrir as portas das universidades para ecoar outras vozes e sabedorias, aquelas que surgem das roças, das aldeias, dos mangues, das matas, dos mares e rios e igarapés para nos ensinar matérias interessantes também se constitui em incerteza, pois os tempos são sombrios no cenário político de nosso país. E de quebra os comentários lacônicos (e posicionamentos preconceituosos!) de colegas acadêmicos afeitos à perspectiva da especialização disciplinar (apenas) ressoam de vez em quando aqui, ali e acolá. A dimensão travessia vem acompanhada de múltiplos significados. Pode ser por causa do mar, tão importante na região bragantina, palco do evento, mas pode significar transformações epistemológicas, pedagógicas, esperanças, mudanças de rumo...

O seminário surgiu em sua primeira versão em Belém, em 2012, e foi organizado pelos Programas de Pós-Graduação em Antropologia (PPGA/IFCH), Agriculturas Amazônicas (PPGAA/INEAF) e Biologia Ambiental (PPBA/Campus de Bragança), contando com a participação de palestrantes da UFPA e de outras instituições, representantes de povos e comunidades tradicionais, grupos de pesquisa e movimentos sociais camponeses. A segunda versão foi organizada pelos grupos de pesquisas ESAC (Estudos Socioambientais Costeiros) e ETHOS (Educação, Trabalho, Tecnologia, Humanidades e Organização Social) da UFPA e do IFPA, respectivamente, ambos de Bragança, envolvendo o Programa de Pós-Graduação em Linguagens e Saberes na Amazônia (PPGLSA)/Campus de Bragança. O marco desse seminário foi o envolvimento da comunidade ribeirinha da Vila Que Era (ou Vila Cuera), que participou ativamente da consecução do seminário, abrindo o espaço da mata-rio para a programação. Durante o evento, ao sabor do vento da maré do rio Caeté e abaixo da sombra de árvores frondosas em pleno céu aberto, crianças, jovens, homens e mulheres e professoras e professores universitários se entrelaçaram nas discussões dos eixos temáticos mobilizados pela comissão organizadora. Aproveitamos esse canal para agradecer vivamente aos colegas de Bragança, as instituições apoiadoras (inclusive a FAPESPA, que disponibilizou recursos), aos grupos artísticos e palestrantes e, de forma muito especial, aos comunitários da Vila Que Era, sem os quais o seminário não teria a mesma magia. Todos os louros e homenagens devem ser dirigidos às pessoas que de alguma forma participaram do encontro e contribuíram para seu sucesso.

Este é o dossiê mais robusto da Amazônica até o presente. De maneira inédita, traz 19 artigos que abordam diversos assuntos. O primeiro deles, como não deveria deixar de ser, apresenta a memória e reflexões teóricas sobre o tema do dossiê, 
sendo escrito por Luís Saraiva, Roberta Barboza, Norma Vieira, Sérgio Cardoso e Jéssica Corrêa. O paper segundo, de Edna Alencar e Isabel de Sousa, retrata a rica experiência etnográfica das autoras em torno dos elementos sociais e ambientais que envolvem o manejo do pirarucu na RDS Mamirauá, no Amazonas. O manuscrito de número três discute e reflete a relação ser humano e natureza, mobilizando também os saberes e processos educativos em torno dos ribeirinhos e ribeirinhas da Comunidade de Sobrado, no Salgado Paraense. Foi escrito por Maria das Graças Silva e Sônia Aleixo. A quarta contribuição nos remete ao sul do Brasil, com o artigo que discute o tema da sociobiodiversidade e das cadeias produtivas no bioma Mata Atlântica. Foi escrito por quatro mulheres: Mariana Ramos, Fabiana Cruz, Gabriela Souza, Rumi Kubo. Açaí juçara, guabiroba, butiá e araçá estão entre esses produtos. Monique Rodrigues e Heribert Schmitz escreveram o quinto artigo, o qual traz um tema muito interessante sobre o conflito social envolvendo a pesca de marrecas numa unidade de conservação de uso sustentável na Amazônia Atlântica Paraense. O artigo de número seis, escrito por Roberth Ferreira e Rubens da Silva tem o tema da pesca como eixo central, ancorado na dimensão da gestão e do acordo de pesca na região da Ilha de São Miguel, em Santarém/PA. O mundo das águas e da pesca na Amazônia surgiram com vigor neste dossiê, e o sétimo manuscrito trouxe a temática do modo de vida entre pescadores artesanais de Alter do Chão, também na região de Santarém, no Pará, tendo sido escrito por Darnisson Silva. Katiane Silva escreveu a oitava contribuição. A antropóloga amazonense nos brinda com as histórias e memórias da pesca do pirarucu na região do Auati-Paraná, na Amazônia Ocidental. Josele da Silva e Tony Braga escreveram em parceria o nono artigo desse número. O tema da etnoictiologia de pescadores artesanais da Reserva Extrativista Tapajós- Arapiuns, no Pará, foi o foco do artigo. O décimo veio da Universidade do Estado do Pará e foi escrito pela professora Betânia Albuquerque. As plantas professoras e suas dimensões educativas, históricas e psíquicas estiveram na essência da contribuição dessa autora. Cleomara Amaral e colaboradores realizaram estudo sobre a importância dos quintais na conservação da agrobiodiversidade e do bioma Cerrado. Esse artigo, o onze, traz a experiência dos agricultores e agricultoras familiares da região da Baixada Cuiabana. O paper décimo segundo, escrito por Francisco de Oliveira, Norma Vieira e Sebastião Rodrigues Jr. discute o tema da família a partir das atividades extrativistas no mangue, ecossistema onde as famílias extraem recursos como madeira, mariscos, caranguejo-uçá, dentre outros. Décima terceira é a ordem do artigo de autoria de Nathália Pereira e Júlio Aguiar, os quais discutem as dimensões do direito e da legitimidade democrática de políticas voltadas para os povos tradicionais. A empiria se passa na Estrada de Ferro Carajás e o Povo Gavião. Bianca Lima e Dalva Mota nos brindam com o décimo quarto artigo do dossiê, que discute o papel de mulheres extrativistas de mangaba como chefes de família numa comunidade da Ilha do Marajó. Edileuza Pillett é a autora do artigo de número quinze, que traz o tema do gênero, 
partindo de sua pesquisa realizada na Reserva Extrativista Caeté/Taperaçu. Nívia Costa e colaboradoras desenvolveram o manuscrito décimo sexto com o tema da etnofísica, o qual aborda a dimensão do diálogo entre os saberes de construtores de barcos e a Física enquanto disciplina científica. Jackson Damasceno Jr. e Rumi Kubo escreveram o artigo de número dezessete, o qual mobiliza o tema da renda em padrões tradicionais entre povos quilombolas e agricultores e agricultoras familiares no Maranhão. Roberta Barboza e colaboradores se reuniram para escrever o artigo dezoito, o qual mobiliza a temática da etnozoologia a partir das representações sociais de pescadores sobre tartarugas marinhas do litoral bragantino/PA. O derradeiro artigo (número dezenove), que fecha este dossiê com chave de ouro, é de autoria de Francisco Apurinã, da Universidade de Brasília, autor indígena. $\mathrm{O}$ manuscrito nos instiga a refletir sobre a prática etnográfica a partir de sua experiência profissional e pessoal. Por fim, os olhos dos leitores e leitoras irão apreciar os cinco ensaios fotográficos que compõem este dossiê. O primeiro ensaio retrata a relação entre mulheres Baré, Tukano e Piratapuia e as plantas na região do Rio Cuieiras, afluente do Rio Negro. Thiago Cardoso trouxe fotografias em preto e branco sobre o cotidiano dessas mulheres. O ensaio fotográfico de número dois é de autoria de uma antropóloga Matsé, Roldan Dunu Tumi Dësi, Nicholas Kawa e Sydney Silverstein, o qual apresenta a experiência do regresso ao lar da primeira autora após anos longe da aldeia para se formar antropóloga numa Universidade peruana. Samuel Rosário e Luís Saraiva são os autores do ensaio terceiro, que apresenta imagens que retratam a etnomatemática através do trabalho minucioso de uma comunidade ribeirinha que transforma a argila em cerâmica caeteuara (em homenagem ao rio Caeté). O quarto ensaio fotográfico é de autoria de Dionísio Sampaio e Colin Beasley e retrata o cotidiano da atividade pesqueira em vários territórios do salgado paraense, como Salinópolis/PA, Augusto Corrêa/PA e Curuçá/PA. O último ensaio é uma viva tradução imagética da prática de fazer beiju na semana santa junto a comunidade de Araí, em Augusto Corrêa/PA. Agradecemos a todos e todas que submeteram seus textos a este dossiê. Tecemos agradecimentos aos pareceristas que ajudaram com as avaliações e aos editores-chefes da revista, pelo apoio a este número especial desde sempre. Somos gratos ainda à equipe técnica da revista, que é crucial para a rapidez na publicação, bem como a qualidade e eficiência técnica do periódico. Por fim, desejamos uma viagem prazerosa pelas páginas da revista e que o Glorioso São Benedito e as águas doces do rio Caeté continuem nos ajudando a animar processos pedagógicos e de pesquisa diferenciados. Que este dossiê possa se espalhar por toda a Amazônia, Brasil e mundo. Uma aprazivel leitura a todos e todas! Obrigado!

Os organizadores. 